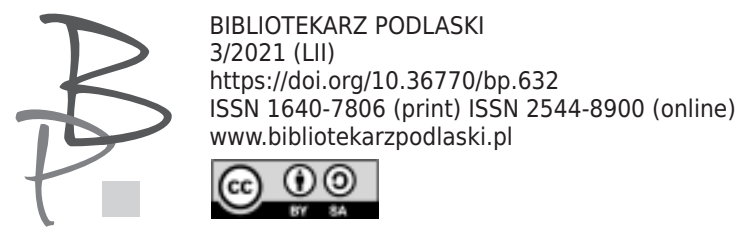

Dariusz Piechota*

Uniwersytet w Białymstoku, Polska / University of Białystok, Poland

ORCID: 0000-0002-7943-384X

\title{
Długie trwanie wieku XIX - (pop)kulturowe rekonstrukcje przeszłości w najnowszej fantastyce
}

The long duration of the nineteenth century - (pop)cultural reconstructions of the past in the latest fiction

Abstract: Contemporary popular culture eagerly returns to the era of steam and electricity. The pop-culture imagery of the nineteenth century functions in two variants (realistic and fantastic) and takes the form of intertextual games, providing material for postmodern collages and remixes. New genres, such as steampunk and mashup, were quickly adapted and modified by Polish writers. Victorians were replaced by positivists who saw modern inventions as an effective weapon in the fight against the invaders. In addition to works presenting an alternative history of the January Uprising, fantasy authors eagerly refer to the works of Bolesław Prus. The further fate of The Doll appears both in the steampunk and mashup conventions. An interesting realization of the mashup is also the anthology Other worlds, inspired by the works of Jakub Różalski, which combine fantasy with realistic poetics straight from the paintings of Józef Chełmoński. In the alternative world of Polish graphics there appear monstrous machines, characters from another dimension (like dwarfs).

Keywords: alternative history, steampunk, mashup, positivism.

\footnotetext{
* Dariusz Piechota - dr, asystent na Uniwersytecie w Białymstoku, autor dwóch monografii, m.in. Pozytywistów spotkania z natura. Szkice ekokrytyczne (2018).
} 
Nie ulega wątpliwości, że współczesna kultura popularna obsesyjnie powraca do epoki pary i elektryczności. Nawiązania do la belle époque obserwujemy nie tylko w literaturze, ale również w filmie ${ }^{1}$, serialach telewizyjnych ${ }^{2}$, komik$\mathrm{sie}^{3}$ czy modzie ${ }^{4}$. Bohaterowie drugiej połowy XIX wieku zamieszkują prze-

1 Na przełomie XX i XXI wieku sfilmowano niemalże wszystkie najważniejsze dzieła wiktoriańskich pisarzy: Charlesa Dickensa, sióstr Brontë, Thomasa Hardy'ego, Wilkie Collinsa, Elizabeth Gaskell, Williama Thackeraya. Por. D. Babilas, Wiktoria znaczy zwycięstwo. Kulturowe oblicza brytyjskiej królowej, Warszawa 2012, s. 192.

2 Najnowsze seriale nawiązujące do ,epoki pary i elektryczności” możemy podzielić na dwie grupy. Pierwszą z nich stanowią produkcje będące adaptacją klasyki [m.in. Nędznicy (2018); Ania, nie Anna (2017-2019) nawiązujący do cyklu powieści (pierwszy tom Ania z Zielonego Wzgórza) Lucy Maud Montgomery; Dracula (2020)] oraz literatury określanej jako neowikoriańska [np. serial Grace i Grace (2017) oparty na powieści Margaret Atwood; Alienista (2018) inspirowany utworem Caleba Carra)]. Drugim wariantem stają się seriale obyczajowe odwołujące się do realiów społecznych, kulturowych wieku XIX [m.in. The English Game (2020), ukazujący transformacje zachodzące w postrzeganiu piłki nożnej jako sportu zarezerwowanego dla klasy wyższej].

3 B. Szleszyński, Komiksowe gry z wiekiem XIX, [w:] Przerabianie XIX wieku. Studia, red. E. Paczoska i B. Szleszyński, Warszawa 2011, s. 246-270.

4 Moda stanowi istotny element świata subkultury steampunkowej, której przedstawiciele uwielbiają oryginalne stroje, nawiązujące do epoki wiktoriańskiej. Nurt ten narodził się pod koniec lat 90. XX wieku, zaś najważniejszą jego postacią stał się Kit Stølen; kostiumolog, projektant, który stworzył nowy trend w modzie, inspirowany stylem epoki pary i elektryczności. Na marginesie mówiąc, wiele osób, wykorzystujących w swoim wizerunku rekwizyty typowe dla wiktorian, nie jest świadoma istnienia związku między modą a literaturą. Steampunkowa moda wydaje się intrygującym połączeniem punkowej estetyki DIY (Do It Yourself) z elegancją. Marzenia przedstawicieli tego nurtu, związane z produkcją przedmiotów, które będzie można przekazać kolejnym pokoleniom, korespondują z poglądami Johna Ruskina, przeciwstawiającego się opresji nowoczesnej kultury przemysłowej. Współcześni twórcy, podobnie jak William Morris, pragną realizować marzenie o wspólnocie wytwórców pięknych przedmiotów. Charakteryzując modę steampunkową, możemy wyróżnić 4 popularne style ubierania się: 1) uliczny urwis, noszący tanie oraz funkcjonalne ubrania kupowane w second-handach. W stylu tym nie obowiązują żadne zasady oprócz funkcjonalnego Do It Yourself; 2) majsterkowicz, dla którego najważniejszym elementem stroju są kieszenie wypełnione akcesoriami; 3) odkrywca - najczęściej nosi wysokie buty z cholewami, gogle w stylu DIY, kobiety zaś preferują wiktoriańskie gorsety. Ubrania w tym stylu pokryte są licznymi zapinkami oraz sprzączkami, a najważniejszym dodatkiem jest zegarek kieszonkowy; 4) esteta uosabiający neowiktoriańską nostalgię za życiem w bohemie artystycznej. Kobiety w tym stylu przypominają męskich dandysów, noszą więc kamizelki, marynarki, fulary. Mężczyźni zaś stylizują się na gotyckich arystokratów. Esteci przywiązują szczególną wagę do licznych akcesoriów (np. metalowe pudełka na papierosy, haftowane chusteczki do nosa). Więcej na ten temat piszą: J. VanderMeer i S. J. Chambers, The Steampunk Bible. An Illustrated Guide to the World of Imaginary Airships, Corsets and Goggles, Mad Scientist and Strange Literature, New York 2011; D. Piechota, Moda retro w zwierciadle steampunku, „Fragile. Pismo Kulturalne” 2014, nr 1(23), s. 100-102. 
strzeń masowej wyobraźni ${ }^{5}$; protagoniści thrillerów medycznych przypominają dziewiętnastowiecznych szalonych naukowców à la dr Frankenstein czy dr Moreau, którzy w nowoczesnych laboratoriach oraz klinikach przeprowadzają nielegalne eksperymenty na ludzkim ciele, często też pracują nad bronią masowego rażenia ${ }^{6}$. Detektywi z kryminałów retro, tropiący seryjnych morderców, przypominają Sherlocka Holmesa ${ }^{7}$. Oprócz boomu na powieści detektywistyczne warto również wspomnieć o figurze wampira, niezwykle popularnej w pierwszej dekadzie XXI wieku dzięki sadze Zmierzch Stephenie Meyer, którą zekranizowano oraz serialom Czysta krew (2008-2014) oraz Pamiętniki wampirów (2009-2017). Dodajmy, że na ich wizerunki miała wpływ popkultura, gdyż to w jej przestrzeni oraz mediów (między innymi kina, komiksu, role playing games), jak pisze Adam Mazurkiewicz, rozgrywa się współczesny dyskurs o przeszłości ${ }^{8}$.

Zmiany w postrzeganiu XIX wieku wynikają nie tylko z nowych propozycji interpretacyjnych zaproponowanych przez badaczy kultury i literatury niniejszego stulecia, ale przede wszystkim z ewolucji kontekstów, towarzyszących recepcji fenomenu la belle époque ${ }^{9}$. Interesujący wydaje się fakt, że popkulturowe wyobrażenia niniejszej epoki bazują głównie na kulturze wiktoriańskiej. To ona stała się wzorcem do snucia opowieści na temat przeszłości, w której centrum zainteresowania znalazły się dokonujące się w drugiej połowie XIX wieku w Anglii przemiany społeczno-obyczajowe. Twórcy nurtu określanego jako neowiktoriański ${ }^{10}$ chętnie odkrywają zapomniane historie, często wykluczone z oficjalnego obiegu, przełamują tematy tabu (na przykład sceny erotyczne), co służy głównie egzemplifikacji tezy, że epoka wiktoriańska jest ważnym lustrem naszej współczesnej epoki. Wspomnijmy choćby o powieściach Sarah Waters [Muskając aksamit (1998), Złodziejka (2002)],

5 E. Paczoska, B. Szleszyński, Przedmowa, [w:] Przerabianie XIX wieku ..., s. 11.

6 A. Trześniewska-Nowak, Wizerunek lekarza w amerykańskich thrillerach medycznych jako rewers XIX-wiecznych powieści grozy, [w:] Reaktywacje dziewiętnastowieczności, red. A. DuninDudkowska, A. Trześniewska-Nowak, D. Piechota, Lublin 2021, s. 89-103.

7 M. Kosmala, Kryminalne retroświaty, [w:] Przerabianie XIX wieku ..., s. 220.

8 A. Mazurkiewicz, (Pop)kulturowe trwanie wieku XIX. Casus: literatura kryminalna, „Acta Universitatis Lodziensis. Folia Litteraria Polonica” 2018, nr 4(50), s. 130.

9 Tamże, s. 129.

10 L. Hadley, Neo-Victorian Fiction and Historical Narrative: The Victorians and Us, Houndmills: Macmillan 2010. 
w których bohaterowie odrzucają tradycyjne role społeczne, porzucają opresyjne środowiska w poszukiwaniu przestrzeni wolności, będącej synonimem szczęścia. Anglia drugiej połowy XIX wieku to świat licznych kontrastów. Obok dzielnic nędzy z licznymi domami publicznymi powstają luksusowe rezydencje arystokratów oraz magnatów finansowych [Szkarłatny platek i biały (2002) Michela Fabera]. Wraz ze sformułowaniem przez Darwina teorii ewolucji wiktorianie musieli dokonać rewizji pojęcia natury; człowiek stał się częścią globalnego przedstawienia, w którym jedne istoty giną, a następnie inne zajmują ich miejsce ${ }^{11}$. Prace angielskiego uczonego wpłynęły na intelektualne życie ludzi drugiej połowy XIX wieku, przyczyniając się do licznych dylematów dotyczących pogodzenia dwóch światów: ludzkiego i zwierzęcego. Problem ten pojawia się w bestsellerowej powieści Wąż z Essex (2016) Sarah Perry, w której główna bohaterka przeprowadza się na prowincję, gdzie prawdopodobnie mityczny stwór powrócił do przybrzeżnej parafii Aldwinter. Cora, entuzjastka ówczesnych badań paleontologicznych, decyduje się na odnalezienie tajemniczego stworzenia, które postrzega jako przedstawiciela wymarłego gatunku. Jednocześnie protagonistka musi zmierzyć się z zabobonami oraz masową histerią lokalnych mieszkańców, odrzucających wszelkie racjonalne argumenty dotyczące tajemniczego węża. Konfrontacja wiary i nauki w powieści Perry odzwierciedla liczne dylematy towarzyszące wiktorianom w drugiej połowie XIX wieku.

Wiktoriański Londyn to także stolica zbrodni, której ikoną staje się Kuba Rozpruwacz ${ }^{12}$, nieuchwytny seryjny morderca polujący pod osłoną nocy na prostytutki. Motyw ten został również powielony w Alieniście (2018) Caleba Carra. Akcja powieści rozgrywa się w Nowym Jorku w 1896 roku, kiedy to metropolią wstrząsają makabryczne morderstwa chłopców-prostytutek. Oprócz śledztwa prowadzonego przez skorumpowaną policję, przyszły prezydent Stanów Zjednoczonych powołuje specjalną komisję prowadzącą prywatne śledztwo. Postacią niezwykle interesującą w powieści jest dr Laszlo Kreizer, psycholog sądowy, przypominający współczesnego profilera, tworzącego por-

11 R. Koziołek, Kompleks Darwina, „Teksty Drugie” 2011, nr 3, s. 8.

12 E. Paczoska, Stolica „świata zwyrodniałego”. Londyn w literaturze angielskiej i polskiej początków XX wieku (z rzutem oka na następne stulecie), [w:] tejże, Prawdziwy koniec XIX wieku. Śladami nowoczesności, Warszawa 2010, s. 63. 
tret psychologiczny mordercy. Utwór Carra to ciekawe studium socjologiczne Ameryki schyłku XIX wieku wraz z dokładną charakterystyką początków tworzenia nowoczesnych metod wykorzystywanych w kryminalistyce (daktyloskopia). Uwagę czytelnika przykuwa także postać Sarah Howard, współpracującej z Kreizerem, marzącej o założeniu własnej firmy detektywistycznej.

Wiek XIX powraca w kulturze popularnej nie tylko w konwencji realistycznej, ale przede wszystkim fantastycznej. Reaktywacje te są ciekawsze, gdyż przyjmują one formę intertekstualnych gier, dostarczających materiału do postmodernistycznych przebieranek, kolaży, powtórzeń, charakterystycznych dla literackiego patchwork $u^{13}$. W obrębie fantastyki spod znaku pop możemy wskazać trzy nowe gatunki (historia alternatywna, steampunk, mushup), które szczególnie popularne stały się na przełomie pierwszej i drugiej dekady nowego stulecia. Gatunki te, jak podkreśla Adam Mazurkiewicz, stanowią „hybrydę genologiczną", powstałą z kontaminacji powieści historycznej i różnych gatunków literatury popularnej ${ }^{14}$. Warto podkreślić, że zjawisko zacierania granicy między sztuką wysoką i niską wiąże się także z kulturą remiksu oraz nurtem recyklingu klasyki literackiej ${ }^{15}$.

Utwory spod znaku historii alternatywnych oraz steampunku szybko pojawiły się na gruncie polskim, a ich twórcy dokonali lokalnej modyfikacji, zwracając uwagę na specyfikę sytuacji politycznej Polski w XIX wieku (zabory) oraz nawiązując do znaczących wydarzeń historycznych i postaci utożsamianych z epoką pozytywizmu ${ }^{16}$. Dodajmy, że polski steampunk, jak pisze Natalia Lemann, „bardzo silnie pozycjonuje się wobec spuścizny romantyzmu (mesjanizm, bunt, byronizm), nicując narodowe klisze i mity w poszukiwaniu odpowiedzi na pytanie, czy mogło być inaczej" ${ }^{17}$. Nie dziwi zatem fakt,

13 E. Paczoska, Uwagi końcowe, [w:] tejże, Prawdziwy koniec XIX wieku ..., s. 263.

14 A. Mazurkiewicz, Polska wspótczesna powieść historyczna i kultura popularna (prolegomena), „Czytanie Literatury. Łódzkie Studia Literaturoznawcze” 2016, nr 5, s. 21.

15 A. Nacher, Remiks i mashup - o niełatwym współbrzmieniu dwóch cyberkulturowych metafor, „Przegląd Kulturoznawczy” 2011, nr 1(9), s. 77-89; D. Piechota, Horror (Neo)Victorianum. Zombie w zwierciadle mashupu, „Przegląd Humanistyczny” 2015, nr 3(450), s. 117-126; A. Depta, Literacki mashup w Polsce. „Przedwiośnie żywych trupów” Stefana Żeromskiego i Kamila Śmiatkowskiego i „Faraon wampirów” Bolesława Prusa i Konrada T. Lewandowskiego jako polskie realizacje gatunku, [w:] Rejestry kultury, red. K. Olkusz, Wrocław 2019, s. 595-613.

16 N. Lemann, Polski steampunk - zaadaptować historię, adaptując konwencję, „Biblioteka Postscriptum Polonistycznego" 2015, nr 5, s. 135.

17 Tamże, s. 137-138. 
że w centrum zainteresowania twórców historii alternatywnych znalazło się powstanie styczniowe. W 2013 roku w 150. rocznicę jego wybuchu w serii „Zwrotnice czasu: Historie alternatywne” ukazały się dwie powieści poświęcone temu wydarzeniu: Orzet bielszy niż gotębica Konrada T. Lewandowskiego oraz Gambit Wielopolskiego Adama Przechrzty ${ }^{18}$.

W pierwszej z nich, utrzymanej w konwencji steampunkowej, Polska wygrywa powstanie dzięki nowoczesnej broni skonstruowanej przez Ignacego Łukasiewicza. Twardochody, czyli parowe czołgi napędzane ropą oraz wodą utlenioną zapewniły rodakom zwycięstwo, lecz niepodległość kraju jest ciągle zagrożona, gdyż Rosjanie szykują się do kontrofensywy. Sytuację niepewności podkreślają licznie pojawiające się w tekście akcenty militarne (zarówno polskie, jak i imperialne) $)^{19}$. Najcenniejsi dla kraju okazują się naukowcy (Ignacy Łukasiewicz oraz James Maxwell), którzy objęci zostają ochroną. Zwycięskie maszyny noszą imiona narodowych wieszczów - Adam I i II, Juliusz, Zygmunt. Powstaje Narodowy Kościół Polski, a naczelnikiem państwa jest Romuald Traugutt. W alternatywnej historii kraju u Lewandowskiego kluczową rolę odgrywa pianola, umożliwiająca kontakt z równoległym światem. Autor wykorzystuje popularny motyw double-blind what if, czyli ,podwójnej ślepej” historii alternatywnej, polegający na tym, że postać żyjąca w historii alternatywnej snuje wizję na temat odmiennego przebiegu wydarzeń, który jest tak naprawdę realizacją rzeczywistej historii ${ }^{20}$. Przenikając do alternatywnego (realnego) świata Traugutt decyduje się na męczeńską śmierć na stokach Cytadeli.

Motyw równoległych światów pojawia się także w drugiej powieści nawiązującej do powstania styczniowego. Akcja utworu Przechrzty rozgrywa się w XXII wieku w Imperium Rosyjskim. W świecie tym nie było ani rewolucji

18 M. Górecka, Historie alternatywne w konwencji steampunk $i$ cyberpunk - wariacje na temat powstania styczniowego w powieściach Konrada T. Lewandowskiego i Adama Przechrzty, „Acta Humana” 2013, nr 4, s. 27-48; N. Lemann, dz. cyt., s. 139-143; A. Trześniewska, Podróż po steampunkowej Warszawie z powieścia Konrada T. Lewandowskiego „Orzel bielszy niż gotębica", [w:] Kanon i obrzeża realizmu, red. J. Szcześniak, A. Skała, Lublin 2016, s. 221-234; J. Rusin, Bohater w epoce „,twardochów”. Kreacja Romualda Traugutta w powieści „, Orzet bielszy niż gołębica” Konrada T. Lewandowskiego, „UR Journal of Humanities and Social Sciences”2020, nr 1(14), s. 31-44.

19 A. Trześniewska, dz. cyt., s. 225.

20 M. Górecka, dz. cyt., s. 41. 
bolszewickiej ani dwóch wojen światowych. Rosjanie dysponują Centrum Symulacji Rzeczywistości, dzięki któremu mogą świadomie modyfikować historię. Dodatkowo nowoczesne komputery wyszukują, a następnie eliminują tak zwanych jokerów, czyli ludzi mających realną możliwość zmiany biegu świata. W Gambicie Wielopolskiego odnajdujemy czytelną aluzję do Konrada Wallenroda Adama Mickiewicza (najwybitniejszym jokerem w historii jest Czachowski, który stoi na czele organizacji spiskowej o nazwie Konrad Wallenrod ${ }^{21}$ ).

Historie alternatywne z powstaniem styczniowym w tle nie tylko zachęcają do refleksji nad sensem zrywów narodowowyzwoleńczych, przybliżając losy wybitnych rodaków, ale również dzięki nowoczesnej formule gatunkowej osadzonej w popkulturze spełniają funkcję edukacyjną. Być może atrakcyjna fabuła, liczne zwroty akcji charakterystyczne dla współczesnych filmów oraz powieści sensacyjnych zachęcą młodsze pokolenie (i nie tylko) do powrotu do tekstów poruszających tematykę powstania.

Postacią, która zawładnęła masową wyobraźnią jest Bolesław Prus, a dokładniej twórczość tego wybitnego pisarza epoki pary i elektryczności. Mowa oczywiście o Lalce, która wkroczyła do kultury popularnej, stając się źródłem licznych przeróbek i kolaży. W 2012 roku w 100. rocznicę śmierci pisarza na rynku wydawniczym pojawiły się dwa utwory nawiązujące do arcypowieści. Pierwszym z nich, utrzymanym w stylistyce steampunku, jest Alkaloid Aleksandra Głowackiego. Utwór ten obfituje w liczne zwroty akcji, co koresponduje z fenomenem współczesnej popkultury, będącej zlepkiem komiksów o amerykańskich superbohaterach, teledysków z MTV oraz produkcji spod znaku Quentina Tarantino ${ }^{22}$. Wokulski w wersji pop staje się multimiliarderem dzięki odkrytej substancji, zwanej alką. Ten magiczny produkt okazał się towarem priorytetowym na całym globie, używają go najwybitniejsi tego świata, jak: Juliusz Verne, Zygmunt Freud oraz papież. Podobnie jak w Lalce, protagonista Alkaloidu nie jest postacią jednowymiarową; to kolekcjoner sztuki, uczestnik tajnych misji, niezwykle inteligentny i przebiegły w prowadzonych transakcjach handlowych.

21 N. Lemann, dz. cyt., s. 143.

22 D. Piechota, W otchłani Alki. Dalsze losy Wokulskiego w świetle steampunku, [w:] tegoż, Między utopia a melancholia. W kręgu nowoczesnej i ponowoczesnej literatury fantastycznej, Lublin 2015, s. 91. 
Drugą powieścią, wydaną w 2012 roku, ukazującą alternatywne życie protagonisty utworu Prusa jest Córka Wokulskiego Romana Praszyńskiego ${ }^{23}$. Stanowi ona literacki patchwork, a sam autor wydaje się zachęcać czytelnika do podjęcia gry, w której odbiorca ma za zadanie rozszyfrować jak najwięcej aluzji literackich i kulturowych wpisanych w tekst powieści. Nawiasem mówiąc, liczne aluzje oraz nawiązania pojawiające się w Córce Wokulskiego odnoszą się także do współczesnej kultury masowej. I tak Izabela Łęcka oraz Ernest Walter, trudniący się okradaniem bogaczy, przypominają Bonnie Parker i Clyde’a Barrowa, parę amerykańskich przestępców z lat 30. XX wieku. Ubodzy mieszkańcy Powiśla budzą skojarzenia ze współczesnym wizerunkiem zombie, rodem z teledysku Thriller Michaela Jacksona czy serialu The Walking Dead. W przestrzeni Warszawy spotykają się postacie realne (Sienkiewicz, Zapolska) z fikcyjnymi (Ochocki, pani Arnoldowa z Emancypantek Prusa). Na marginesie wspomnijmy również o utworze Lalki (2013) Alicji Pruś, będącej rodzajem retrokryminału. W kamienicy, należącej do Krzeszowskich, mają miejsce tajemnicze morderstwa. Ich zagadkę próbują rozwiązać studenci oraz pani Meliton, którzy przypominają słynną parę detektywów Sherlocka Holmesa i doktora Watsona. Mimo że utwory te noszą cechy grafomańskie, stanowią one rodzaj postmodernistycznej gry, zabawy z arcydziełem Prusa. Pomysły autorów na rozwijanie wątków arcypowieści z wykorzystaniem popularnych klisz, fabuł, struktur typowych dla romansu, thrillera czy powieści detektywistycznej świadczą o jej żywotności w przestrzeni popkultury.

Do Lalki nawiązuje również Jacek Dukaj w powieści Imperium chmur (2018), łączącej w sobie elementy charakterystyczne dla historii alternatywnej z japońską estetyką, obecną na wielu płaszczyznach utworu. Akcja powieści rozgrywa się w Japonii, w której planowane są kolejne strategie wojny z Rosją. Wokulski (Wo Ku Kyi), emisariusz z Kraju, Który Nie Istnieje przybywa do cesarza Mutschito z misją poparcia sprawy polskiej w walce o niepodległość. Jest on jednym ze spadkobierców zmarłego w Paryżu Geista i posiada informacje na temat skutecznej broni (Żelaznego Ducha). To właśnie w Hokkaido rozpoczyna się masowa produkcja podniebnych maszyn, oparta na wynalazku naukowca (metalu lżejszego od powietrza). Nowoczesny sprzęt zapewni

23 D. Piechota, „Córka Wokulskiego” Romana Praszyńskiego jako literacki patchwork, „Ogród. Kwartalnik Humanistyczny” 2017, nr 1-4, s. 139-178. 
Japonii cywilizacyjną przewagę nad resztą świata. Podobnie jak w Alkaloidzie Wokulski jest biznesmenem inwestującym majątek w naukowe projekty. W przeciwieństwie do Lalki bohater pełni marginalną rolę w Imperium Chmur, a na pierwszy plan wysuwa się Ochocki (O Ho Kyi), któremu towarzyszy główna bohaterka. Kiyoko uczestniczy we wszystkich kluczowych wydarzeniach, ponieważ pełni rolę tłumacza, zapisującego uwagi i spostrzeżenia naukowców. W powieści Dukaja interesujący jest obraz Japonii, otwierającej się na cywilizację zachodnią. Wspomnijmy choćby doktora Aka, który żyje „życiem zachodnich barbarzyńców”24. Jego dom został zbudowany na „europejską modłę ${ }^{25}$. Z kolei zachodnie trendy w modzie namiętnie śledzi żona naukowca.

W przeciwieństwie do utworów Głowackiego, Praszyńskiego czy Prusa Imperium chmur wyróżnia się oryginalną formą, gdyż nadrzędnym celem dla Dukaja stało się stworzenie haiku prozą. Struktura powieści opiera się na licznych kontrastach, wynikających między innymi z połączenia skrótowości gatunkowej haiku z rozbudowaną epickością. Liczne niedopowiedzenia (charakterystyczne dla kultury japońskiej) przeplatane są w utworze z rozległymi opisami (typowymi dla cywilizacji zachodniej). Opozycja ta szczególnie widoczna jest w zestawieniu głównych bohaterów: Kiyoko oraz braci Ochockich. Protagonistka utworu okazuje się introwertyczką, której refleksje oraz spostrzeżenia pełne są niejasnych i mało czytelnych dla Europejczyków symboli. Jej styl życia nasuwa skojarzenia ze średniowiecznymi ascetami. Z kolei synowie Ochockiego to ekstrawertycy, którzy w imię górnolotnych haseł dążą wprost do autodestrukcji.

Postmodernistyczne zabawy z twórczością Prusa obejmują nie tylko Lalkę, ale również Faraona. W 2012 roku ukazała się powieść Faraon wampirów Bolesława Prusa i Konrada T. Lewandowskiego ${ }^{26}$, przypominająca literacki $m a-$ shup. Gatunek ten, podobnie jak steampunk czy historie alternatywne, stanowi nie tylko ciekawą zabawę z wiekiem XIX, ale również „ożywia” zapomniane teksty, wzbogacając je w wartość naddaną. Zjawisko mashupu odzwierciedla

24 J. Dukaj, Imperium chmur, [w:] Inne Światy. Antologia inspirowana pracami Jakuba Różalskiego, Kraków 2018, s. 419.

25 Tamże.

26 Więcej na ten temat piszą: A. Trześniewska, Alternatywna wizja spoleczeństwa starożytnego Egiptu w „Faraonie wampirów” Konrada T. Lewandowskiego, [w:] Bolesław Prus. Pomiędzy tekstami, red. D. Piechota, A. Trześniewska, Lublin 2017, s. 245-263; A. Depta, dz. cyt., s. 565-613. 
także obecną we współczesnej kulturze popularnej obsesję retromanii, obejmującą muzykę, literaturę, film ${ }^{27}$, nasilającą się wraz z globalnym zasięgiem Internetu. Uczestniczymy w niekończącym się recyklingu, w którym dokonują się różnego rodzaju remiksy, kontaminacje utworów reprezentujących różne gatunki. Zacieranie granicy między tym, co wysokie, a tym co masowe jest zabiegiem celowym, gdyż ich twórcom przyświeca zasada: wprowadzić czytelnika w zdumienie z powodu przełamywania konwencji. Mashup to ciekawe zjawisko kulturowe, którego celem jest eksperymentowanie z klasyką oraz zachęcenie młodego (i nie tylko) czytelnika do podjęcia indywidualnej interpretacji utworu. Wspomniana zabawa z oryginalnym tekstem polega na wprowadzeniu do niego pewnej modyfikacji (na przykład postaci wampira, zombie). Jak podają niektóre podręczniki creative writing: mashup powinien zawierać $80 \%$ oryginalnego tekstu, zaś pozostałe $20 \%$ stanowią wątki fantastyczne ${ }^{28}$. Lewandowski dokonał swoistej dekonstrukcji Faraona; wyciął z powieści opisy Egiptu, rozwinął niektóre epizody (jak choćby konsekwencje klątwy rzuconej przez Dagona na Sarę). Alternatywny świat faraonów zamieszkują mumie, hybrydy, wampiry. Akcja utworu koncentruje się na walce o władzę oraz doprowadzenie do transformacji Ramzesa XIII w wampira.

Interesującą realizację mashupu reprezentuje antologia Inne światy (2018), inspirowana pracami Jakuba Różalskiego, polskiego grafika, malarza, ilustratora. Jego najsłynniejszy projekt $1920+$ przedstawia alternatywne uniwersum, w którym autor łączy wątki polskiej armii (motyw kawalerii) z codziennym życiem wsi, utrwalonej w malarstwie przełomu XIX i XX wieku. Różalski nie ukrywa fascynacji obrazami Józefa Chełmońskiego i Aleksandra Gierymskiego. Tematyka jego prac koncentruje się na środowisku wiejskim, a sam twórca, podobnie jak Chełmoński, wydaje się być wnikliwym obserwatorem codziennej egzystencji osób pracujących na polu [Droga Mleczna ${ }^{29}$, Żeglarz (s. 132133), Żniwiarka (s. 141), Przedwiośnie (s. 206)]. Sielską atmosferę zakłócają pojawiające się w przestrzeni rodzimych łąk, pól, gór monstrualne maszyny,

27 S. Reynolds, Retromania. Jak popkultura żywi się własna przeszłościa, przeł. F. Łobodziński, Warszawa 2018, s. 7.

28 J. Murphy, Remix Culture and Literary Mashup, https://www.alluvium-journal.org/2013/03/26/remix-culture-and-the-literary-mashup/ [data dostępu: 10.04.2021].

29 Inne światy. Antologia inspirowana pracami Jakuba Różalskiego, Kraków 2018, s. 20. Cytaty lokuję w tekście. 
wywołujące u niektórych z obrazów zdziwienie (a nawet przerażenie). Zastosowany przez Różalskiego zabieg nie tylko przełamuje konwencję realistyczną, ale przede wszystkim buduje atmosferę grozy. Wydaje się, że tajemnicze machiny pochodzą z innego wymiaru i zapowiadają nadciągający kataklizm. W alternatywnym świecie polskiego grafika pojawiają się także postacie fantastyczne jak krasnale, wkraczające w świat ludzi [Futrzany demon (s. 384-285), Konkurenci (s. 391)].

Uniwersum stworzone przez Różalskiego nie jest jednorodne, co potwierdza antologia Inne światy, do której współtworzenia zaproszono współczesnych pisarzy od Sylwii Chutnik, Remigiusza Mroza, Jakuba Żulczyka po Łukasza Orbitowskiego, Jakuba Małeckiego. W tomie tym opublikowano wcześniej omawiane przeze mnie Imperium chmur. Aluzje do Lalki Prusa pojawiają się także w opowiadaniu Człowiek, który kochał Anny Kańtoch. Akcja utworu rozgrywa się w pierwszej połowie XX wieku, a jednym z jej głównych bohaterów jest pułkownik Ochocki, który kontroluje prace naukowe w zamkniętym ośrodku znajdującym się na terenie dawnego warszawskiego ogrodu botanicznego. Warto podkreślić, że miejsce to jest pilnie strzeżone i tylko nieliczni mają do niego dostęp. Podobnie jak w powieściach poruszających alternatywną historię powstania styczniowego, w utworze Kańtoch naukowcy pracują nad machiną umożliwiającą nie tylko podróżowanie w czasie, ale także ingerencję w wydarzenia historyczne. W rozmowie z księciem Sobieskim Ochocki stwierdza:

[...] czas jest materią, a Maszyna krosnem, za pomocą którego można, ujmijmy to tak, naprawić wadliwy ścieg. [...] Zawsze znajdzie się coś, co można by poprawić, jakaś nitka dziejów, która inaczej pociągnięta, doprowadziłaby nasz kraj w odmienne miejsce. Moglibyśmy być potęgą... ${ }^{30}$.

Niepokojący wydaje się fakt, że nowoczesne urządzenie może nie tylko zmienić bieg historii, ale posłużyć jako broń w walce o dominację na arenie międzynarodowej.

W antologii Inne światy pojawia się także opowiadanie nawiązujące do literatury romantycznej, a dokładnie do motywu wilkołaka, który, jak pisze Maria Janion, jest jednym z przykładów metamorfozy zwierzęcej, odsłaniającej

30 A. Kańtoch, Człowiek, który kochat, [w:] Inne światy..., s. 208 
szczególny rodzaj trwogi zbiorowej ${ }^{31}$, wynikający z wiary w likanotropię. Orbitowski w Sforze modyfikuje ten popularny motyw w popkulturze, a bohaterem jego utworu jest skóra wilka, która posiada magiczne właściwości. U osób, które decydują się ją założyć, obserwujemy wzrost kreatywności i pewności siebie. $Z$ jednej strony zapewnia ona sukcesy w życiu zawodowym, z drugiej zaś działa niczym narkotyk na jednostkę. Przywołajmy choćby postać Wolfganga, który za dnia jest przykładnym ojcem, czytającym dziecku powieści Juliusza Verne’a oraz Jacka Londona. Nocą zaś, za sprawą skóry, przeobraża się w maniaka seksualnego, polującego na kolejne ofiary. Motyw ten stanowi czytelną kalkę z utworu Niezwykty przypadek doktora Jekylla i pana Hyde'a (1886) Roberta Louisa Stevensona. Postać tajemniczego mordercy uaktywnia pierwotne lęki wśród lokalnego społeczeństwa: „Szeptały coś o bestii, o wilczym diable zesłanym przez Boga za grzech budowy Nowej Huty. [...] Opowiadano sobie historie o czarnej wołdze porywającej dzieci"'32.

Alternatywna opowieść o życiu krasnoludków pojawia się w noweli Tyle lat trudu Jakuba Żulczyka. Jej bohaterem jest Baryła, który wraz z kolegami decyduje się opuścić las w celu poszukiwania pożywienia. Wyprawie tej towarzyszą ironiczne komentarze na temat konsumpcyjnego stylu życia ludzi. Krasnal stwierdza: „[...] sto lat temu prawie wyginęliśmy przez rozwój motoryzacji [...] Generalnie to musimy iść do tego śmietnika, bo nie ma co żryć, nasi naprawdę już korę z drzew obgryzają"33. Żulczyk przełamuje nie tylko konwencję realistyczną poprzez wprowadzenie postaci baśniowych, ale również zaburza hierarchię poziomów narracyjnych. W połowie historii wkracza grafik, który rysując Baryłę rozpoczyna dialog z postacią fikcyjną. Wtargnięcie metaświata do noweli burzy pierwotny porządek świata. Rodzi się kolejne pytanie: kto jest twórcą świata przedstawionego? W utworze Żulczyka obecne są również intertekstualne odniesienia do popkultury. Pojawiająca się w zakończeniu tajemnicza postać przybywająca do Baryły z misją ocalenia świata nasuwa skojarzenia z bohaterem Władcy pierścieni Tolkiena:

31 M. Janion, Wampir. Biografia symboliczna, Gdańsk 2008, s. 161.

32 Ł. Orbitowski, Sfora, [w:] Inne światy..., s. 284.

33 J. Żulczyk, Tyle lat trudu, [w:] Inne światy..., s. 387. 
Naszą krainę pustoszy Władca Ciemności. Wysyła orki, które gwałcą księżniczki i urywają łby jednorożcom. Dzieciom baby mleka nie mogą dać. Krowom rosną puste cyce zamiast oczu. Potworny jest mór i zaraza. Magiczne jezioro połknęło jeźdźca Rolanda i pękła na cztery pradawna cytra IIniaeth. Mam tu magiczny pierścień, który musisz zanieść do Góry Przeznaczenia i wrzucić do środka, po drodze pokonać od cholery trolli, zmor i innych zaraz, i wtedy wszystko będzie gitara - mówi na bezdechu, jakby się bał, że jak powie to wolniej, zapomni co ma powiedziećc ${ }^{34}$.

Misja krasnala jest oczywiście misją à rebours. Pojawiające się odwołania do powieści Tolkiena mają charakter ironiczno-satyryczny. Powielane przez Żulczyka klisze noszą znamiona kiczu, potęgującego efekt sztuczności, przez co utwór ten nabiera charakteru karykaturalnego.

Najnowsza polska fantastyka chętnie powraca do wieku XIX. Reaktywacjom epoki pary i elektryczności sprzyjają nowe gatunki, jak steampunk i mashup, które szybko zostały spopularyzowane i zaadaptowane w rodzimej literaturze popularnej. Wiktorian zastąpili pozytywiści, upatrujący w wynalazkach tajemniczej i skutecznej broni w walce z zaborcami. Twórcy fantastyki w wersji pop często nawiązują do kluczowych wydarzeń z tamtego okresu (między innymi powstania styczniowego) oraz Lalki Prusa, utworu żyjącego w zbiorowej świadomości. Włączanie arcypowieści w najróżnorodniejsze obiegi kultury „ożywia” oryginał oraz zachęca czytelników do jej ponownej lektury. Nie dziwi zatem fakt, że bohaterem wielu historii alternatywnych stał się Stanisław Wokulski. Mimo że w wielu przypadkach to grafomańskie utwory z Lalką w tle (Alkaloid Głowackiego, Córka Wokulskiego Praszyńskiego) są one interesujące, gdyż wpisują się w poetykę postmodernistycznej gry z arcydziełem, w której to dopisywane są niektóre wątki, inne zaś usuwane z powieści (w Faraonie wampirów Lewandowskiego). Autorzy chętnie posługują się popularnymi kliszami, fabułami, strukturami charakterystycznymi dla romansu, thrillera czy powieści detektywistycznej. Zacierające się granice między poszczególnymi gatunkami tworzą „hybrydy genologiczne”, które z perspektywy marketingowej są zabiegiem celowym, gdyż poszerzają krąg odbiorców nie tylko o miłośników dziejów minionych ${ }^{35}$. Utwory te często nasuwają

34 Tamże, s. 406.

35 A. Mazurkiewicz, Polska współczesna powieść historyczna..., s. 21. 
skojarzenia z konstrukcją patchworkowa czy palimpsestem, na który składają się różne opowieści o przeszłości. $Z$ jednej strony zabawy z tekstem kanonicznym stanowią formę żartu literackiego, z drugiej zaś odzwierciedlają obecne w popkulturowej imaginacji zjawisko recyklingu, nieustannego ,przerabiania” utworów, odwoływania się do tekstów kultury masowej. Ciągle czekamy nie tylko na współczesną polską wersję powieści neowiktoriańskiej w stylu Szkartatnego płatka i białego, która zerwie ze stereotypowym postrzeganiem literatury drugiej połowy XIX wieku, odsłoni zapomniane historie oraz bohaterów, przełamie tematy tabu, ale również na ambitną wersję fantastyki, inspirowaną epoką pary i elektryczności.

\section{Bibliografia}

\section{Literatura podmiotu}

Dukaj J., Imperium chmur, [w:] Inne Światy. Antologia inspirowana pracami Jakuba Różalskiego, Kraków 2018.

Głowacki A., Alkaloid, Warszawa 2012.

Kańtoch A., Człowiek, który kochał, [w:] Inne Światy. Antologia inspirowana pracami Jakuba Różalskiego, Kraków 2018.

Lewandowski K. L., Orzeł bielszy niż gołębica, Warszawa 2013.

Orbitowski Ł., Sfora, [w:] Inne Światy. Antologia inspirowana pracami Jakuba Różalskiego, Kraków 2018.

Praszyński R., Córka Wokulskiego, Warszawa 2012.

Prus B. i Lewandowski K. T., Faraon wampirów, Warszawa 2012.

Przechrzta A., Gambit Wielopolskiego, Warszawa 2013.

Żulczyk J., Tyle lat trudu, [w:] Inne Światy. Antologia inspirowana pracami Jakuba Różalskiego, Kraków 2018.

\section{Literatura przedmiotu}

Babilas D., Wiktoria znaczy zwycięstwo. Kulturowe oblicza brytyjskiej królowej, Warszawa 2012

Depta A., Literacki mashup w Polsce. „Przedwiośnie żywych trupów” Stefana Żeromskiego i Kamila Śmiałkowskiego i „Faraon wampirów” Bolesława Prusa i Kon- 
rada T. Lewandowskiego jako polskie realizacje gatunku, [w:] Rejestry kultury, red. K. Olkusz, Wrocław 2019.

Górecka M., Historie alternatywne w konwencji steampunk i cyberpunk - wariacje na temat powstania styczniowego w powieściach Konrada T. Lewandowskiego i Adama Przechrzty, „Acta Humana” 2013, nr 4.

Hadley L., Neo-Victorian Fiction and Historical Narrative: The Victorians and Us, Houndmills:Macmillan 2010.

Janion J., Wampir. Biografia symboliczna, Gdańsk 2008.

Kosmala M., Kryminalne retroświaty, [w:] Przerabianie XIX wieku. Studia, red. E. Paczoska i B. Szleszyński, Warszawa 2011.

Koziołek R., Kompleks Darwina, „Teksty Drugie” 2011, nr 3.

Lemann N., Polski steampunk - zaadaptować historię, adaptując konwencję, „Biblioteka Postscriptum Polonistycznego" 2015, nr 5.

Mazurkiewicz A., Polska współczesna powieść historyczna i kultura popularna (prolegomena), „Czytanie Literatury. Łódzkie Studia Literaturoznawcze” 2016, nr 5.

Mazurkiewicz A., (Pop)kulturowe trwanie wieku XIX. Casus: literatura kryminalna, „Acta Universitatis Lodziensis. Folia Litteraria Polonica”, 2018, nr 4(50).

Murphy J., Remix Culture and Literary Mashup https://www.alluvium-journal. org/2013/03/26/remix-culture-and-the-literary-mashup/ [data dostępu: 10.04.2021].

Nacher A., Remiks i mashup - o niełatwym współbrzmieniu dwóch cyberkulturowych metafor, „Przegląd Kulturoznawczy” 2011, nr 1(9).

Paczoska E., Stolica „świata zwyrodniałego”. Londyn w literaturze angielskiej i polskiej początków XX wieku (z rzutem oka na następne stulecie), [w:] tejże, Prawdziwy koniec XIX wieku. Śladami nowoczesności, Warszawa 2010.

Piechota D., "Córka Wokulskiego" Romana Praszyńskiego jako literacki patchwork, „Ogród. Kwartalnik Humanistyczny" 2017, nr 1-4.

Piechota D., Horror (Neo)Victorianum. Zombie w zwierciadle mashupu, „Przegląd Humanistyczny" 2015, nr 3(450).

Piechota D., Moda retro w zwierciadle steampunku, „Fragile. Pismo Kulturalne” 2014, nr 1(23).

Piechota D., W otchłani Alki. Dalsze losy Wokulskiego w świetle steampunku, [w:] tegoż, Między utopią a melancholią. W kręgu nowoczesnej i ponowoczesnej literatury fantastycznej, Lublin 2015.

Reynolds S., Retromania. Jak popkultura żywi się własną przeszłością, przeł. F. Łobodziński, Warszawa 2018. 
Rusin J., Bohater w epoce "twardochów”. Kreacja Romualda Traugutta w powieści "Orzeł bielszy niż gołębica" Konrada T. Lewandowskiego, „UR Journal of Humanities and Social Sciences" 2020, nr 1(14).

Szleszyński B., Komiksowe gry z wiekiem XIX, [w:] Przerabianie XIX wieku. Studia, red. E. Paczoska i B. Szleszyński, Warszawa 2011, s. 246-270.

Trześniewska A., Alternatywna wizja społeczeństwa starożytnego Egiptu w „Faraonie wampirów" Konrada T. Lewandowskiego, [w:] Bolesław Prus. Pomiędzy tekstami, red. D. Piechota, A. Trześniewska, Lublin 2017.

Trześniewska A., Podróż po steampunkowej Warszawie z powieścią Konrada T. Lewandowskiego „Orzeł bielszy niż gołębica”, [w:] Kanon i obrzeża realizmu, red. J. Szcześniak, A. Skała, Lublin 2016.

Trześniewska-Nowak A., Wizerunek lekarza w amerykańskich thrillerach medycznych jako rewers XIX-wiecznych powieści grozy, [w:] Reaktywacje dziewiętnastowieczności, red. A. Dunin-Dudkowska, A. Trześniewska-Nowak, D. Piechota, Lublin 2021. 